Marquette University

e-Publications@Marquette

College of Nursing Faculty Research and

Publications

Nursing, College of

$10-1-2008$

\title{
Loneliness: A Concept Analysis
}

Abir K. Bekhet

Marquette University, abir.bekhet@marquette.edu

Jaclene A. Zauszniewski

Case Western Reserve University

Accepted version. Nursing Forum, Vol. 43, No. 4 (October 2008): 207-213. DOI. (C) 2008 Nursecom, Inc. Used with permission.

Abir K. Bekhet was affiliated with Case Western Reserve University, Frances Payne Bolton School of Nursing at the time of publication. 


\section{Marquette University \\ e-Publications@Marquette}

\section{Nursing Faculty Research and Publications/College of Nursing}

This paper is NOT THE PUBLISHED VERSION; but the author's final, peer-reviewed manuscript. The published version may be accessed by following the link in the citation below.

Nursing Forum, Vol. 43, No. 4 (October/December 2008): 207-213. DOI. This article is (C Wiley and permission has been granted for this version to appear in e-Publications@Marquette. Wiley does not grant permission for this article to be further copied/distributed or hosted elsewhere without the express permission from Wiley.

\section{Contents}

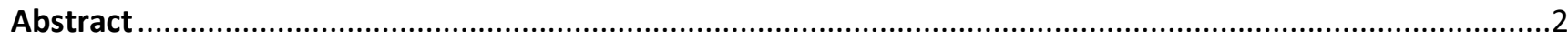

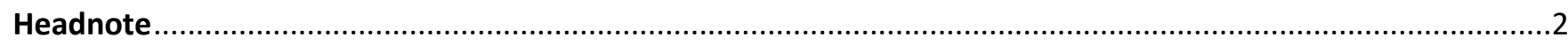

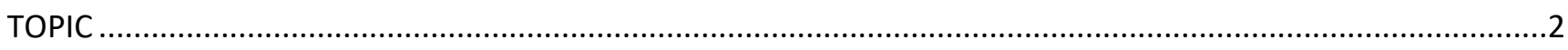

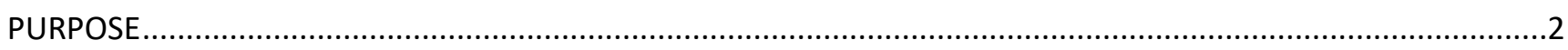

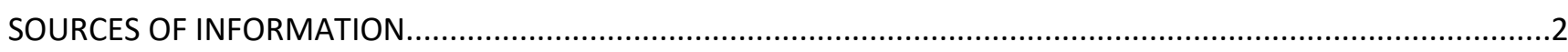

CONCLUSION

Search terms

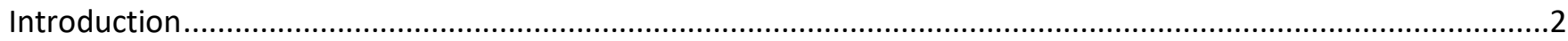

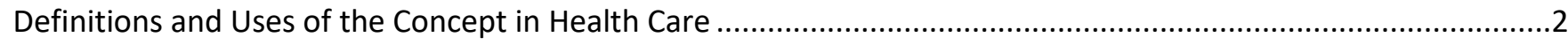

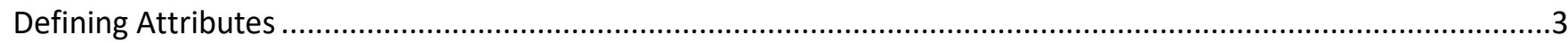

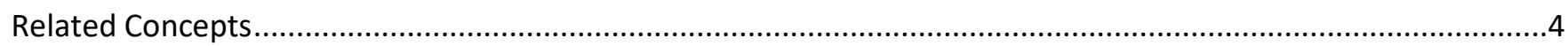

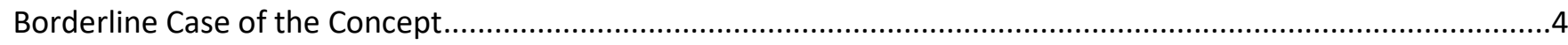

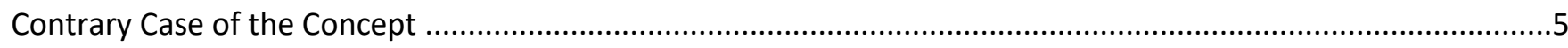

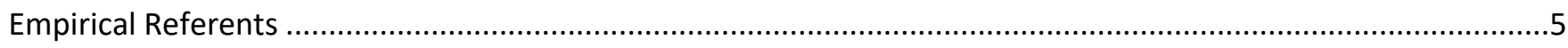

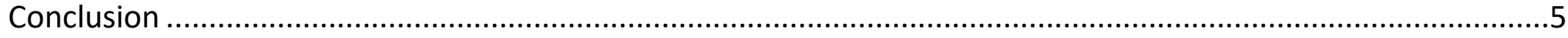

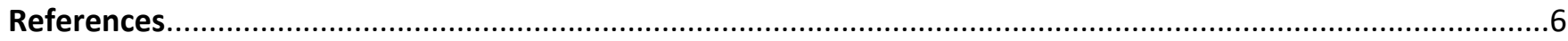




\title{
Loneliness: A Concept Analysis
}

\author{
Abir K. Bekhet \\ Case Western Reserve University \\ Jaclene A. Zauszniewski \\ Case Western Reserve University \\ Wagdy E. Nakhla \\ Victoria Hospital, Alexandria, Egypt.
}

\begin{abstract}
Loneliness is a universal human experience recognized since the dawn of time, yet it is unique for every individual. Loneliness can lead to both depression and low self-esteem. This article explicates the concept of loneliness through the examination of its conceptual definition and uses, defining attributes, related concepts, and empirical referents. Literature review using hand search and database were used as sources of information. Because loneliness is commonly encountered in nursing situations, the information provided will serve as a framework for assessment, planning, intervention, and evaluation of clients.
\end{abstract}

\section{Headnote}

TOPIC. Loneliness is a universal human experience recognized since the dawn of time, yet it is unique for every individual. Loneliness can lead to both depression and low self-esteem.

PURPOSE. This article explicates the concept of loneliness through the examination of its conceptual definition and uses, defining attributes, related concepts, and empirical referents.

SOURCES OF INFORMATION. Literature review using hand search and database were used as sources of information.

CONCLUSION. Because loneliness is commonly encountered in nursing situations, the information provided will serve as a framework for assessment, planning, intervention, and evaluation of clients.

Search terms: Concept, loneliness, nursing

\section{Introduction}

Loneliness is a universal human experience recognized since the dawn of time (Copel, 1988), yet it is unique for every individual (Austin, 1989). It can be seen as a negative, embarrassing condition, as painful and even dreadful (Killeen, 1998). This article explicates the concept of loneliness through examination of its uses, defining attributes, related concepts, antecedents, consequences, measures, and theories. Because loneliness is a problem commonly encountered in nursing situations, the information provided here can serve as a framework for assessment, planning, intervention, and evaluation of clients.

\section{Definitions and Uses of the Concept in Health Care}

Loneliness has been addressed in studies of several types of clients, including children with learning disabilities (Margalit, 1998), people with mental illness (Brown, 1996), elderly with hearing loss (Chen, 1994), people with physical disabilities (2006), and residents of long-term care facilities (2005). It has also been examined in clients with 
Alzheimer's disease (Berman, 1994), veterans with AIDS (Nokes \& Kendrew, 1990), women who were abused (2006), older people with cerebral palsy (2006), older women who were battered (2005), men and women who were homeless (2005), and women with radical mastectomy (Hogstel, 1982). Loneliness has been defined as an emotional state in which an individual is aware of the feeling of being apart from another or others, along with the experience of a vague need for individuals (Copel, 1988). Loneliness has also been defined as an unwelcome feeling of lack of companionship and a wish for interaction different from that being experienced (Francis, 1976). Younger (1995) noted that loneliness is the feeling of being alone in spite of longing for others, while Portnoff (1988) defined loneliness as the experience of isolation, disorientation, or "lostness" within a dimensional domain of meaning. Ryan and Patterson (1987) pointed out that in contemporary literature, loneliness is defined as the unpleasant experience that occurs when a person's network of social relationships is deficient either qualitatively or quantitatively. Loneliness is a pervasive, depressing, debilitating condition that can affect all of one's life" (Killeen, 1998). It is described by the lonely as an "emptiness" or "hollow feeling" (Austin, 1989). Also, Killeen (1998) suggests that loneliness is unique for every individual and called it "the difficult-to-define concept." The term loneliness was first used by Sigmund Freud in 1939 to describe the inner structure of the person that could be completely changed after an experience of loneliness. Years later, Sullivan elaborated on Freud's description of loneliness; he proposed that humans are social animals with a need for contact and that loneliness is the result of this unfulfilled need (Copel, 1988; Sullivan, 1953).

There is still no consensus on the definition of loneliness. Different definitions of loneliness have been proposed by various investigators to understand its nature, though, all definitions involve three assumptions. First, loneliness results from perceived deficiencies in one's social world. Second, loneliness is a subjective state, as distinguished from the objective state of social isolation. Third, the experience of loneliness is unpleasant and distressing (Carr \& Schellenbach, 1993; Kraus, Davis, Bazzini, \& Church, 1993; Younger, 1995).

Three major types of loneliness have been identified: existential, pathological, and psychosocial. Existential loneliness is a universal human characteristic, inborn in all persons and not related to object loss or lack of intimate relationships. Existential loneliness is also referred to in the literature as primary loneliness (Austin, 1989; Francis, 1976). Pathological loneliness is thought to be related to dysfunctional cognitions and affective states, usually experienced by severely disturbed and psychotic individuals, mainly schizophrenic patients (Austin, 1989). Psychosocial or ordinary loneliness is often a product of situational change or temporary separation. It is global, generalized, and uncomfortable. Psychosocial loneliness is also referred to as secondary loneliness (Carr \& Schellenbach, 1993).

Anybody and everybody can be lonely at any time. However, the elderly and adolescents are especially prone to loneliness. The literature suggests that loneliness in the elderly is more related to loss than to isolation. Old age is characterized by multiple losses that occur together or in quick succession. Lack of a spouse and close friends, lack of belonging and employment, as well as decline in income and physical dysfunction, all contribute to loneliness in the elderly (Austin, 1989; Ryan \& Patterson, 1987). In contrast, loneliness in preadolescence and adolescence may be the result of lack of friendship, acceptance, and intimate exchanges with a friend or a loving person (Davis, 1990).

\section{Defining Attributes}

In order to distinguish loneliness from other related concepts, it is essential to identify its defining characteristics (Walker \& Avant, 1995). Rokach (1988) pointed to four major elements of the experience of loneliness: self alienation, interpersonal isolation, distressed reactions, and agony. None of these elements is in itself specific to loneliness; however, the four elements combine to create the experience of loneliness (Rokach, 1988). Self-alienation, which is a feeling of separation from one's self, core, and identity (Rokach, 1988), has two components: emptiness and depersonalization. Emptiness is the hollowness and blackness felt by the lonely, while depersonalization is characterized by a feeling of unreality and confused identity (Rokach, 1988). Interpersonal isolation refers to the feeling of being emotionally, geographically, and socially alone; it has three components: absence of intimacy, perceived social alienation, and abandonment. Absence of intimacy is a disturbing feature of loneliness; it refers to the lack of a close, intimate, and caring relationship. Absence of intimacy has two components: a lack of closeness to 
others in general. This component focuses on deficiency in relationships in general and missing a specific relationship, i.e., a person who is no longer present, or the absence of any intimate relationship in one's life (Rokach, 1988).

Perceived social alienation refers to the perception of being socially unwanted and alone, or abandoned. Perceived social alienation has two components: disconnectedness and social rejection. Disconnectedness refers to the feeling of being socially and emotionally detached from others; social rejection refers to the actual rejection that is often felt by the lonely (Rokach, 1988). Abandonment refers to the person's belief that he or she was purposefully left behind or abandoned. Abandonment also has two components: intimate rejection and betrayal. Intimate rejection refers to the feeling of rejection by close and intimate persons (e.g., mother, girlfriend); betrayal is a generalized feeling of being unaccepted and unwelcomed by others.

The distress experienced by the lonely has four components: physiological and behavioral distress, self-deprecation, self-generated social detachment, and immobilization. Physiological and behavioral distress involves somatic complaints such as headaches, nausea, or stomach upset, or behavioral stress such as crying and sleeping more than usual. Self-deprecation refers to a generalized negative attitude toward one's self. Self-generated social detachment reflects a lack of closeness to others that is brought on oneself, and it has two components: withdrawal and active separation. Withdrawal reflects the need to become uninvolved in a "gentle manner"; active separation refers to more aggressive detachment or "refusing to open up."

The term agony factor describes the lonely person's pain and suffering. Its components include inner turmoil and emotional upheaval. Inner turmoil indicates inner searching for answers and insights, and includes three components: defenselessness, confusion, and numbness. Defenselessness reflects the person's inner disturbance and despair. Confusion involves feeling mixed up, not thinking correctly, and numbness describes the way one feels as a result of loneliness. Emotional upheaval refers to the emotions revolving around pain and suffering, including anxiety, fear, anger, hostility, and concern about future existence, as well as feelings of embarrassment, shame, and humiliation (Rokach, 1988).

\section{Related Concepts}

The research literature suggests that loneliness is a consequence or correlate of numerous variables. Loneliness has been found to be negatively related to self-esteem and positively related to depression, i.e., lonely persons have been found to be relatively depressed and their self-esteem was low (Ouellet \& Joshi, 1986; Roscoe \& Skomski, 1989). A positive relationship has also been found between anxiety and loneliness. Jackson and Cochran (1991) found a positive relationship between the subjective experience of loneliness and impaired mental health, including neuroticism, low self-esteem, depression, anxiety, psychosomatic concern, and aggression. Significant associations have also been found between shyness, lower extroversion, and loneliness. A person who is shy may find difficulty in relating to others and in expressing his or her thoughts and emotions, which may contribute to the feeling of loneliness (Kalliopuska, 1986). Finally, significant relationships have been reported between loneliness and physical problems, and greater age-related increases in blood pressure and poorer sleep quality were found in lonely older adults (Cacioppo et al., 2002).

\section{Borderline Case of the Concept}

A borderline case of the concept includes some, but not all, of its critical attributes or it may contain additional attributes (Walker \& Avant, 1995). There is a confusing relationship between loneliness and alienation. Loneliness refers to the subjective experience of separation from someone or something that one is attached to, while alienation refers to the objective or physical separation from that person or thing. Francis (1976) stated that "alienation may well be the objective aspect of loneliness ... which is quite subjective."

Aloneness is another confusing and overlapping concept. Loneliness is a feeling of being by oneself. The person has no choice and does not want to be in that condition. On the other hand, the term aloneness indicates that there is an element of choice in wanting to be by oneself.

Aloneness has an active nature, while loneliness is a passive experience (Killeen, 1998). 
Social isolation is another concept in the literature that may be confused with loneliness. Social isolation reflects a condition that may contain elements of loneliness or aloneness, depending on whether choice is involved. In other words, social isolation with choice is aloneness, while social isolation without choice is loneliness (Killeen, 1998).

Solitude is another borderline case of the concept. It has a more optimistic sense; it does not carry the negative connotation of loneliness. Solitude is perceived as refreshing and calming; it can be seen when people "take time out" to feel closer to nature, or to find themselves. It indicates total freedom of choice and it is very useful in coping with loneliness (Younger, 1995).

Estrangement is another borderline case of the concept of loneliness. Estrangement indicates a further cutoff from society, and one finds it very difficult to get back in (Killeen, 1998).

\section{Contrary Case of the Concept}

In contrary cases of the concept, none of the critical attributes of the concept are present (Walker \& Avant, 1995). Connectedness is thought to be a contrary concept. Younger (1995) defined connectedness as "a sense of being in touch with the eternal, of recognizing unity between self and others, of being a part of something that is greater than ourselves. It is being at one with timelessness, self, and others. In fact, connecting is the spirit's desire to belong to someone or something, somewhere. Friendship, marriage, parenting, and church are all manifestations of the need for belonging where persons of similar values and competence meet. Belonging gives one meaning in life (Younger, 1995).

\section{Empirical Referents}

Empirical referents represent the operational definitions of the conceptual variables (Zauszniewski, 1995). Empirical referents have also been defined as the actual instruments or experimental conditions used in a study (Fawcett \& Downs, 1986). It assists the clinician to predict the existence of a concept in particular clients (Walker \& Avant, 1995). Empirical referents for loneliness include a lack of or problems with social relationships, and self-labeling, complaints, inability to make decisions, and a focus on weakness in self or others (Copel, 1988). Problems with social relationships can be identified by subjective comments that indicate lack of companionship: absence, separation, or loss, and lack of perceived human contact or support. Selflabeling refers to negative self-talk that indicates low self-esteem or selfworth (Copel, 1988).

The revised UCLA loneliness scale (RULS) is one way to measure the subjective experience of loneliness. The RULS is a 20-item, 4-point scale with responses ranging from J have never felt this way (1) to J have felt this way often (4). Total scores range from 20 to 80 . The RULS includes 10 items reflecting satisfaction with social relationships and 10 reflecting dissatisfaction (two subscales). The scores of items that are positively worded are reversed before summing (Kim, 1999), so that the higher the score, the greater the loneliness.

Coefficient alpha was greater than 80 for various adolescent samples (Foxall, Barron, Dollen, Jones, \& Shull, 1992). The scale was used for elderly Korean women living in the United States and found to be reliable (Cronbach's alpha = 0.95). The loneliness scale has been used in recent studies (Cacioppo, Hughes, Waite, Hawkley, \& Thisted, 2006; Hughes \& Cacioppo, 2004). The loneliness scale is a 3-item scale designed to gauge feelings of social isolation within the constraints of a short telephone interview. The scale consists of three questions. An example is "How often do you feel that you lack companionship?" Response categories are coded: 1 = hardly ever, 2 = some of the time, and $3=$ often. Each person's responses to the three questions are summed, with higher scores indicating greater loneliness. The coefficient alpha was reported to be 0.73 , and the total score was correlated with the full loneliness scale $(r=$ $0.82, \mathrm{p}<.0001)$.

\section{Conclusion}

The phenomenon of feeling lonely as a lived experience is not adequately addressed in the nursing literature (Karnick, 2005). Analysis of its defining attributes and empirical referents provides important information related to its clinical usefulness, particularly, identification of risk factors of loneliness. Stressors that generate tension can be assessed and 
the information derived can be used as a basis for nursing intervention. By identifying persons who are experiencing loneliness and who are at risk, appropriate intervention can be initiated.

It has been documented that the prognosis for depression in the elderly is poor when it is accompanied by loneliness; the feeling of loneliness leads to more pronounced motivational depletion and to "giving up" (Stek et al., 2005). This in turn may have serious consequences, including reduced self-care, decreased mobility, poor diet, and reduced compliance with a prescribed drug regimen, all possible pathways to early death (Stek et al., 2005). Clearly, nurses need to assess those who are at risk for developing loneliness and develop interventions that involve clients in more sociable activities based on their age and degree of illness. Although the RULS is a reliable and valid measure, it should be tested with more diverse populations and with persons of varying ages and diseases in order to determine its cultural relevance.

\section{Sidebars}

Loneliness has been defined as an emotional state in which an individual is aware of the feeling of being apart from another or others, along with the experience of a vague need for individuals

Finally, significant relationships have been reported between loneliness and physical problems, and greater age-related increases in blood pressure and poorer sleep quality were found in lonely older adults

Empirical referents for loneliness include a lack of or problems with social relationships, and self-labeling, complaints, inability to make decisions, and a focus on weakness in self or others

Clearly, nurses need to assess those who are at risk for developing loneliness and develop interventions that involve clients in more sociable activities based on their age and degree of illness.

\section{References}

Arokach, A. (2006). Alienation and domestic abuse: How abused women cope with loneliness. Social Indicators Research, 78(2), 327-340.

Austin, A. G. (1989). Becoming immune to loneliness: Helping the elderly fill a void. Journal of Gerontological Nursing, 25(9), 2530.

Balandin, S., Berg, N., \& Waller, A. (2006). Assessing the loneliness of older people with cerebral palsy. Disability \& Rehabilitation, 28(8), 469-479.

Banks, M., \& Banks, W. (2005). The effects of group and individual animal-assisted therapy on loneliness in residents of long term care facilities. Anthrozoos, 18(4), 396-408.

Berman, B. F. (1994). Alzheimer's and related disorders: Loneliness, depression and social support of spousal care givers. Journal of Gerontological Nursing, 20(3), 6-16.

Brown, C. (1996). A comparison of living situation and loneliness for people with mental illness. Psychiatric Rehabilitation Journal, 20(2), 59-63.

Cacioppo, J. T., Hawkley, L. C, Crawford, E., Ernst, J. M., Burleson, M. H., Kowalewski, R. B., et al. (2002). Loneliness and health: Potential mechanisms. Psychosomatic Medicine, 64, 407-417.

Cacioppo, J. T., Hughes, M. E., Waite, L. J., Hawkley, L. C, \& Thisted, R. A. (2006). Loneliness as a specific factor for depressive symptoms: Cross-sectional and longitudinal analyses. Psychology and Aging, 21(1), 140-151.

Carr, M., \& Schellenbach, C. (1993). Reflective monitoring in lonely adolescents. Adolescence, 28(111), 737-747.

Chen, H. (1994). Hearing in the elderly: Relation of hearing loss, loneliness, and self-esteem. Journal of Gerontological Nursing, 20(6), 22-28.

Copel, L. C. (1988). Loneliness: A conceptual model. Journal of Psychosocial Nursing and Mental Health Nursing, 26(1), 14-19.

Davis, B. D. (1990). Loneliness in children and adolescents. Issues in Comprehensive Pediatric Nursing, 13, 59-69.

Fawcett, J., \& Downs, F. (1986). Analysis of theory. In J. Fawcett \& F. Downs (Eds.), The relationship of theory and research (pp. 13-52). Norwalk, CT: Appleton-Century-Crofts.

Foxall, M. J., Barron, C. R., Dollen, K. V., Jones, P. A., \& Shull, K. A. (1992). Predictors of loneliness in low vision adults. Western Journal of Nursing Research, 24(1), 86-99. 
Francis, G. M. (1976). Loneliness: Measuring the abstract. International Journal of Nursing Studies, 13(3), 153-160. Hogstel, M. O. (1982). Old, alone, and in need. Journal of Gerontological Nursing, 8, 337-339.

Hughes, M. E., \& Cacioppo, J. T. (2004). A short scale for measuring loneliness in large surveys; results from two population-based studies. Research on Aging, 26, 655-672.

Jackson, J., \& Cochran, S. D. (1991). Loneliness and psychological distress. Journal of Psychology, 125(3), 257-262.

Kalliopuska, M. (1986). Empathy and the experiencing of loneliness. Psychological Reports, 59, 1052-1054.

Karnick, P. M. (2005). Feeling lonely: Theoretical perspectives. Nursing Science Quarterly, 18(1), 7-12.

Killeen, C. (1998). Loneliness: An epidemic in modern society. Journal of Advanced Nursing, 28(4), 762-770.

Kim, O. (1999). Predictors of loneliness in elderly Korean immigrant women living in the United States of America. Journal of Advanced Nursing, 29(5), 1082-1088.

Kraus, L. A., Davis, M. H., Bazzini, D., \& Church, M. (1993). Personal and social influences on loneliness: The mediating effect of social provisions. Social Psychology Quarterly, 56(1), 37-53.

Margalit, M. (1998). Loneliness and coherence among preschool children with learning disabilities. Journal of Learning Disabilities, 31(2), 173-180.

Nokes, K. M., \& Kendrew, J. (1990). Loneliness in veterans with AIDS and its relationship to the development of infections. Archives of Psychiatric Nursing, 4(4), 271-277.

Ouellet, R., \& Joshi, P. (1986). Loneliness in relation to depression and self-esteem. Psychological Reports, 58, 821822.

Portnoff, G. S. (1988). Loneliness: Lost in the landscape of meaning. Journal of Psychology, 222(6), 545-555.

Rokach, A. (1988). The experience of loneliness: A tri-level model. Journal of Psychology, 122(6), 531-544.

Rokach, A. (2005). Private lives in public places: Loneliness of the homeless. Social Indicators Research, 72(1), 99-114.

Rokach, A., Lechcier-Kimel, R., \& Safarov, A. (2006). Loneliness of people with physical disabilities. Social Behavior and Personality, 34(6), 681-700.

Roscoe, B., \& Skomski, G. G. (1989). Loneliness among late adolescents. Adolescence, 24(96), 947-955.

Ryan, M. C, \& Patterson, J. (1987). Loneliness in the elderly. Journal of Gerontological Nursing, 13(5), 6-12.

Stek, M. L., Vinkers, D. J., Gussekloo, J., Beekman, A. T., Van der Mast, R., \& Westendorp, R. G. (2005). Is depression in old age fatal only when people feel lonely? American Journal of Psychiatry. 162(1), 178-180.

Sullivan, H. S. (1953). In H. S. Perry \& M. L. Gawel (Eds.), The interpersonal theory of psychiatry. New York: Norton.

Varcarolis, E. M. (1994). Foundations of psychiatric-mental health nursing (2nd ed.). Philadelphia, PA: W. B. Saunders. Walker, L. O., \& Avant, K. C. (1995). Strategies for theory construction in nursing (3rd ed.). Houston, TX: Appleton \& Lange.

Winterstein, T., \& Eisikovits, Z. (2005). The experience of loneliness of battered old women. Journal of Women \& Aging, 17(4), 3-19.

Younger, J. B. (1995). The alienation of the sufferer. Advances in Nursing Science, 17(4), 53-72.

Zauszniewski, J. A. (1995). Operationalization of a nursing model for psychiatric nursing research. Western Journal of Nursing Research, 17(4), 435-447. 